\title{
SURVEY OF CRIMEAN-CONGO HEMORRHAGIC FEVER VIRUS IN RHIPICEPHALUS AND DERMACENTOR SPECIES TICKS FROM SOUTH-EASTERN ROMANIA
}

\author{
Bianca Brătuleanu ${ }^{1}$, Delphine Chretien ${ }^{1}$, Béatrice Regnault ${ }^{1}$, Sarah Temmam ${ }^{1}$, Philippe \\ Perot $^{1}$, Adriana Anita ${ }^{2}$, Dragos Anita ${ }^{2}$, Gheorghe Savuta ${ }^{2}$, and Marc Eloit ${ }^{1}$ \\ ${ }^{1}$ Institut Pasteur \\ ${ }^{2}$ Universitatea de Stiinte Agricole si Medicina Veterinara Ion Ionescu de la Brad din Iasi
}

June 4, 2020

\begin{abstract}
Few previous studies suggested the circulation of Crimean Congo hemorrhagic fever virus (CCHFV) in Romania, but were based on serological techniques. The present work investigated the presence of CCHFV RNA in Rhipicephalus sp. and Dermacentor sp. ticks, in south-eastern Romania. In July 2019, 127 ticks were collected from the environment and from domestic ruminants (sheep and goats) in five different locations from Tulcea county. All tick samples were tested using Real Time RT-PCR based on SYBR Green with the purpose to detect the CCHFV. For this purpose, specific primer sets for each of the six known CCHFV genotypes and one degenerate primer pair for the detection of all genotypes were used. None of the samples was identified as positive (prevalence $<2,5 \%, \mathrm{p}=0.05$ ), highlighting the nil or the low prevalence of CCHFV RNA in Dermacentor sp. and Rhipicephalus sp. ticks from Tulcea county, in 2019. Further studies based on the serological surveillance of animals and more comprehensive ticks testing by molecular biology methods if CCHFV circulates at very low level in Romania.
\end{abstract}

\section{INTRODUCTION}

Crimean-Congo hemorrhagic fever virus (CCHFV), a orthonairovirus of theNairoviridae family is the causative agent of a severe human hemorrhagic fever disease characterized by fever, weakness, myalgia, and hemorrhagic signs (Bente et al., 2013). The disease, named Crimean hemorrhagic fever was first observed in the Crimean Peninsula in 1944, and the causative agent which was isolated in 1967, was found to be identical to Congo virus isolated in 1956 from a febrile child in the Belgian Congo hence the names Crimean and Congo are used in combination (Casals, 1969). The mean of CCHF fatality rates in Africa (22.0\%) is lower than Asia (33.5\%) and Europe (33.8\%) (Nasirian, 2020). The natural vector and reservoir have been identified as Hyalomma sp. ticks, and the distribution of human cases closely mirrors vector distribution CCHFV has been detected in more than 30 species of ticks, including Dermacentor sp . andRiphicephalus $s p$. ticks (Mehravaran et al., 2013). Studies conducted since then have consistently found a relationship between various tick species (Hyalomma, Rhipicephalus, Boophilus, Dermacentor and Ixodes ) and the presence of CCHFV in ticks are believed to be the principal means of viral transmission and persistence in nature (Drosten, Kummerer, Schmitz, \& Gunther, 2003; Wolfel et al., 2007). Nevertheless, the ability to transmit infection has been demonstrated for ixodid ticks of several genera, and transovarial transmission of the virus from adult females to the succeeding generation of larval ticks has been shown to occur in a few members of the Hyalomma, Dermacentor, and Rhipicephalus genera (Zeller, Cornet, Diop, \& Camicas, 1997).

In south-eastern Romania, the presence of Hyalomma was confirmed in 2014 (Dumitrescu et al., 2014). The coincidence in distribution of CCHF virus and Hyalomma ticks implies that members of this genus are important vectors of the virus (Shepherd, Swanepoel, Cornel, \& Mathee, 1989). Arboviruses usually 
show low levels of genome diversity, perhaps since they have to be adapted both to an arthropod vector and a vertebrate host species, but CCHFV does not follow this rule and shows a high nucleic acid diversity (Weaver, 2006). This virus is a negative-sense, single-stranded RNA virus with a genome of approximative $19.2 \mathrm{~kb}$ in length. The genome contains three segments: small $(\mathrm{S})$, medium $(\mathrm{M})$ and large $(\mathrm{L})$. The $\mathrm{L}$ segment encodes the RNA-dependent RNA polymerase, the M segment encodes the precursor of the two envelope glycoproteins Gn and Gc, and the S segment encodes the nucleocapsid protein (Aitichou, Saleh, McElroy, Schmaljohn, \& Ibrahim, 2005; Estrada \& De Guzman, 2011; Honig, Osborne, \& Nichol, 2004). CCHFV is an enveloped virus characterized by a degree of sequence diversity of $20 \%, 22 \%$, and $31 \%$ among the S-, L-, and M-segments of the virus genome (Bente et al., 2013). M and L RNA segments of nairoviruses are larger than other bunyaviruses (hantaviruses and phleboviruses) (Estrada-Pena et al., 2007; Hoogstraal, 1979). As other members of the family Bunyaviridae, CCHFV glycoproteins target the Golgi apparatus, where most viral assembly takes place. Recent studies have revealed a new strain which shows unique Ssegment phylogenies and which constitutes a unique clade (provisionally identified as clade VII) (Chinikar et al., 2010). Crimean-Congo hemorrhagic virus circulates in nature in unnoticed enzootic tick-vertebrate-tick cycles. Asymptomatic CCHFV infection has been reported in numerous vertebrate species and appears to be pervasive in both wild and domestic animals. Asymptomatic viremia last up to $7-15$ days in several vertebrate animal species, and CCHFV has been isolated from livestock and small mammals (horses, donkeys, goats, cattle, sheep, and pigs (Ergonul, 2006).

In Romania there is still not sufficient data concerning CCHFV and the virus has never been detected in ticks. Virus detection by real-time quantitative reverse transcription polymerase chain reaction (RT-qPCR) is essential to prove an actual circulation of CCHFV in a country and can be used to identify animals and humans CCHFV infections, together with viral detection in ticks. The predominant problem in CCHFV RT-qPCR development has always been the high genetic diversity of the virus (Deyde, Khristova, Rollin, Ksiazek, \& Nichol, 2006).

The aim of this study was to assess the prevalence of CCHFV inDermacentor sp . and Rhipicephalus sp . ticks collected from Romania, more precisely in Tulcea county, where in previous studies IgG antibodies anti-CCHFV were found in sheep and goats (Ceianu, Panculescu-Gatej, Coudrier, \& Bouloy, 2012; Răileanu, Anită, Porea, \& Savuta, 2015).

\section{MATERIAL AND METHODS}

Ticks were collected during July 2019 from different locations in south-eastern Romania. The sampling consisted in environmental and body-surface of domestic ruminants, from five sites across Tulcea county. Tulcea county (latitude: $44.64^{\circ} \mathrm{S}-45.42^{\circ} \mathrm{N}$; longitude: $28.00^{\circ} \mathrm{W}-29.65^{\circ} \mathrm{E}$ ) is situated in southeast Romania and forms the northern part of Dobrogea province. Vegetation is represented by submediterranean broadleaf forests and xerophytic pastures with shrubs. The county is bordered by the river Danube (W and N), and the Black Sea (E), and is neighboring Ukraine (N). Ground-feeding birds and small and larger mammals, including livestock, are abundant in this area.

Questing ticks collection was performed by dragging. The surface covered at each collection sites was 1 hectare and the flag was examined after every $10 \mathrm{~m}$ of dragging, at the end of each segment. Between every $10 \mathrm{~m}$ of dragging, every transect was separated by $20 \mathrm{~m}$. Tick sampling in Tulcea county was performed only once at each site (Table 1). Engorged ticks were collected on domestic ruminants. The whole body of each sampled animal was inspected for the presence of tick infestations by palpation, mainly on the ears and along the nape of the neck, perineum, scrotum or udder, and tail base. Ticks collected from each animal were kept alive in separate vials and labeled. Live ticks were transported in vials (within a closed secondary container) to the laboratory. Prior handling, ticks were cooled by placing the vials in ice. Developmental stages were identified under a stereomicroscope using standard morphological identification keys. After the identification, each tick was cut lengthwise, using sterile scalpels on an ice-cold surface Petri dish, in a class II laminar flow hood. Half was used for additional processing and the remainder was stored at -80degC. Ticks were transferred to Institut Pasteur (Paris, France) and analysed by real time RT-qPCR. For maintaining the integrity of RNA, ticks were introduced in RNA later solution (Invitrogen, France), according to best 
security practices of storing and transport.

\section{RNA extraction}

Extraction steps were conducted in a BSL-3 laboratory. The ticks were pooled based on the geographical region before extraction, resulting a final number of 13 pools (Table 2). The tick pools were homogenized in $2 \mathrm{~mL}$ reinforced tubes MK28-R from Precellys containing $1 \mathrm{ml}$ of TRIzol Reagent for cells.

Ticks were shaken two to three times for 30s using the Minilys (Bertin, France). Between each shaking procedure the samples were placed on ice for 1 minute. The homogenates were used for total RNA extraction. The lysates were centrifuged at $12,000 \mathrm{~g}$ for $2 \mathrm{~min}$ at $4 \mathrm{degC}$. RNA was purified with a RNeasy mini kit (Qiagen, Hilden, Germany) according to the manufacturer's instructions, including on-column DNAse treatment and further analyzed using an Agilent Bioanalyzer. The RNA recovered in nuclease-free water was stored at $-80 \mathrm{deg} C$.

\section{Detection of CCHFV in Dermacentor sp. andRhipicephalus sp. ticks using Real Time RT-PCR based on SYBR Green}

In the present study specific primer sets for each of the six known CCHFV genotypes and one degenerate primer pair for the detection of all genotypes, described by others were used (Sas et al., 2018). These genotypes were assigned to different geographic areas: I - West Africa, II - Central Africa, III - South and West Africa, IV - Asia and Middle East, V- South and East Europe, VI - Europe. The region targeted by these primers was from nucleotide 1068 to 1248 for the S-sequence. Viral RNA was transcribed to cDNA using SuperScript IV Reverse Transcriptase (ref. 18090050, Invitrogen) reagent kit and a 6-mer random primer (ref. N8080127, Invitrogen).

One $\mu \mathrm{l}$ of DNAc, $0.2 \mu \mathrm{l}$ of each CCHF-deg primer, $0,2 \mu \mathrm{l}$ of each genotype-specific CCHF-primer, $10 \mu \mathrm{l}$ SybrGReen reagent and $8.6 \mu \mathrm{l} \mathrm{H2O}$ were used, in a total reaction volume of $20 \mu l$. The real time RT-qPCR was performed with Roche LightCycler 96 System (Roche Diagnostics, Germany). The cycling conditions used as follows: $95^{\circ} \mathrm{C}$ for $300 \mathrm{~s}$ preincubation, followed by 45 cycles at $95^{\circ} \mathrm{C}$ for $10 \mathrm{~s}$ (denaturation), $60^{\circ} \mathrm{C}$ for $10 \mathrm{~s}$ (annealing) $72^{\circ} \mathrm{C}$ for $30 \mathrm{~s}$ and $37^{\circ} \mathrm{C}$ for $30 \mathrm{~s}$ (cooling), the annealing temperature being adjusted at $60^{\circ} \mathrm{C}$ depending on the primers temperature.

For regulatory reasons regarding bioterrorism, it was not possible to use a positive control. A negative control nuclease-free water was used to rule out cross contamination of reagents and surfaces. Analysis of the fluorescence data was conducted with the LightCycler 96 software. Fifteen $\mu$ l of PCR product was mixed with $3 \mu \mathrm{l}$ of loading buffer and then electrophoresed on $2 \%$ agarose gel in Tris-acetate-EDTA buffer.

Statistical analysis : The upper range of prevalence was calculated using VS Outbreak SurveillanceToolbox. The maximal prevalence of viral infection in ticks was estimated assuming a sensitivity of $100 \%$ and a confidence level of $95 \%$.

\section{RESULTS AND DISCUSSION}

During this study a total of 127 ticks were collected. Of these, 47 were identified as Dermacentor $s p$. questing ticks from the environment and 80 were confirmed as Riphicephalus sp. engorged ticks, detached from adult goats and sheeps. All ticks were tested for detection of the six CCHFV genotypes by real time qRT-PCR. For this purpose, real time RT-qPCR based on SybrGreen with specific primer sets for the detection of all the six known CCHFV genotypes (Sas et al., 2018) in questing and engorged ticks were used. The detection of CCHFV consisted in the amplification of a $180 \mathrm{bp}$ region from $\mathrm{S}$ segment that is coding for NP. CCHFV is classified as a risk group 4 pathogen, being considered to have bioterrorism potential due its aerosol infectivity. For regulatory reasons a positive control was not included in reaction. By using the negative control, we have not encountered any false-positive RT-PCR results due to contamination. In all collection sites from Tulcea county, the tested samples using real time qRT-PCR were identified as negative for the six genotypes of CCHFV. The results are listed in table 3. As no positive result was recorded, this defines a maximal prevalence $<2.5 \%(\mathrm{p}=0.05)$. We consider this result as robust because of the good 
sensitivity of the RT-qPCR used in this study. Two copies/ $\mu$ l were detected for genotypes II (DR Congo), IV (Afghanistan), V (Kosovo) and VI (Greece), while the limits of detection for genotypes I and III were 200 copies/ $\mu$ l respectively (Sas et al., 2018). During the same study the specificity was favorably evaluated using ten viruses from the order Bunyavirales as none of the viruses was detected.

The present study highlight the nil or at most low prevalence of CCHFV RNA in Dermacentor sp. and Rhipicephalus sp. questing ticks and engorged ticks from south-eastern Romania, in 2019 from the same region (Tulcea county) where the presence of CCHFV antibodies in animals has been detected previously (Ceianu et al., 2012; Răileanu et al., 2015).

Crimean Congo hemorrhagic fever has a widespread geographic distribution, the disease being reported in many regions of Africa, Middle East, Europe, and Asia, and outbreaks caused by CCHFV have been recorded in several countries (Chinikar et al., 2010). A detailed review about the epidemiology of CCHF in Asia, Europe and Africa was published in 1979 by Hoogstraal (Hoogstraal, 1979).

The Balkan Peninsula is an endemic region for the disease, where Turkey and Bulgaria are countries with the majority of the cases (Estrada-Pena et al., 2007; Honig et al., 2004; Papa, Pappa, Panayotova, Papadopoulou, \& Christova, 2016; Papa et al., 2013; Zeller et al., 1997). In Bulgaria, country that is on the border with Romania, CCHFV has an endemic evolution (Gergova \& Kamarinchev, 2013) which could suggest the circulation of the virus in Romania, possibly by ticks carried on migratory birds or through the international livestock trade. Migratory birds' role in spreading Crimean-Congo hemorrhagic fever virus (CCHFV) through attached ticks was demonstrated in Turkey (Leblebicioglu et al., 2014). The geographic area of our present investigations comprises one of the most active bird migration pathways in southeastern Europe, for both spring and fall migrations.

In livestock the CCHFV does not cause clinical disease. However, domestic animals are very important for the epidemiology of the virus. Sheep have been recognized as CCHFV reservoirs in certain endemic regions, and have been epidemiologically linked to human cases on several occasions (Humolli, Dedushaj, Zupanac, \& Mucaj, 2010; Mostafavi, Haghdoost, Khakifirouz, \& Chinikar, 2013). Not only are they hosts for adult vectors, but they also may amplify the virus and infect other ticks during their short-lived viremia, and thus may introduce the virus into new areas via movement and importation of tick-infested and virus-infected livestock (Gale et al., 2010).

So far, the presence of the CCHFV in ticks from Romania was not confirmed and, consistently with our results, CCHFV human disease has not been reported to date. There are few serological studies regarding the circulation of CCHFV on Romanian territory. In 2012, Ceianu tested 471 sheep serum samples from different localities in Tulcea county and obtained a prevalence of $27.8 \%$ for IgG antibodies against CCHFV (Ceianu et al., 2012). However, a more recent study conducted by Raileanu in 2015, reported an overall prevalence of $74 \%$ IgG antibodies by testing 90 domestic ruminants (Răileanu et al., 2015). In the study conducted by Raileanu 74 Rhipicephalus sp . ticks, collected from the positive animals, were tested using rRT-PCR method obtaining negative results, which suggest the seroconversion process occurred before the ticks were attached and the transmission of the virus to vectors was not achieved (Răileanu et al., 2015). Many studies suggest that the viral RNA in attached ticks does not directly indicate transmission to host species, and vice versa: infected ticks have been found on seronegative animals and uninfected ticks on seropositive animals (Zeller et al., 1997).

The results of this study together with previous published data may suggest a silent tick-vertebrate-tick cycle of CCHFV in Romania. Clinical cases occur when a range of factors related to tick, vertebrate host, and human behavior align, increasing the level of viral circulation, the interactions between humans and sources of infection. Thus, detection of CCHFV antibodies in domestic animals has been important in providing initial evidence of circulating virus and localizing CCHFV and increased risk for human infection (Spengler, Bergeron, \& Rollin, 2016).

There are many factors that can influence the circulation of CHHFV. For example, abiotic variation by season and region is reported in CCHFV evolution (Spengler et al., 2016). Longitudinal studies demonstrated 
considerable variation when repeated sampling was performed in the same location. These studies reported September as the optimum period for detecting antibodies with a notable decrease in seroprevalence in the winter-spring period (Gale et al., 2010). This could also partially explain our negative results, because we collected the ticks only once, in July 2019. Variation in seroprevalence is often associated with competent vector distribution, host preference of competent tick vectors, and tick load on a particular animal species. Hyalomma sp. ticks were not tested, which is a limit of our study. This study can therefore be extended by exploring different tick species, areas and seasons of sampling.

\section{CONCLUSIONS}

Our results highlight that in 2019, the presence of the CCHFV RNA was not detected in Rhipicephalus $s p$. and Dermacentor sp.ticks collected from five different sites in Tulcea county, even if the CCHFV IgG antibodies were identified in animals from this area, during researches undertaken in previous years.

Further studies should focus on increasing the number of collected ticks and also in expanding the geographical area of research, correlated with serological investigations in animals in order to accomplish a longitudinal research for better understanding CCHFV epidemiology throughout Romania.

\section{ACKNOWLEDGMENTS}

We wish to thank DVM Andreea Paula Cozma, DVM Anca Mihaela Dascălu, DVM Ioana Alexandra Rățoi from the Public Health Department, "Ion Ionescu de la Brad" University of Agricultural Sciences and Veterinary Medicine Iasi, Romania for their contribution in this research.

\section{ETHICS STATEMENT}

The authors confirm that the ethical policies of the journal, as noted on the journal's author guidelines page, have been adhered to. No ethical approval was required as this is a review article with no original research data.

\section{CONFLICT OF INTERESTS}

We declare no competing interests.

\section{DATA AVAILABILITY STATEMENT}

The data that support the findings of the study are available on request from the corresponding author.

We declare no competing interests.

\section{REFERENCES}

Aitichou, M., Saleh, S. S., McElroy, A. K., Schmaljohn, C., \& Ibrahim, M. S. (2005). Identification of Dobrava, Hantaan, Seoul, and Puumala viruses by one-step real-time RT-PCR. J Virol Methods, 124 (1-2), 21-26. doi:10.1016/j.jviromet.2004.10.004

Bente, D. A., Forrester, N. L., Watts, D. M., McAuley, A. J., Whitehouse, C. A., \& Bray, M. (2013). Crimean-Congo hemorrhagic fever: history, epidemiology, pathogenesis, clinical syndrome and genetic diversity. Antiviral Res, 100 (1), 159-189. doi:10.1016/j.antiviral.2013.07.006

Casals, J. (1969). Antigenic similarity between the virus causing Crimean hemorrhagic fever and Congo virus. Proc Soc Exp Biol Med, 131 (1), 233-236. doi:10.3181/00379727-131-33847

Ceianu, C. S., Panculescu-Gatej, R. I., Coudrier, D., \& Bouloy, M. (2012). First serologic evidence for the circulation of Crimean-Congo hemorrhagic fever virus in Romania.Vector Borne Zoonotic Dis, 12 (9), 718-721. doi:10.1089/vbz.2011.0768

Chinikar, S., Ghiasi, S. M., Moradi, M., Goya, M. M., Shirzadi, M. R., Zeinali, M., . . . Bouloy, M. (2010). Geographical distribution and surveillance of Crimean-Congo hemorrhagic fever in Iran. Vector Borne Zoonotic Dis, 10 (7), 705-708. doi:10.1089/vbz.2009.0247 
Deyde, V. M., Khristova, M. L., Rollin, P. E., Ksiazek, T. G., \& Nichol, S. T. (2006). Crimean-Congo hemorrhagic fever virus genomics and global diversity. J Virol, 80 (17), 8834-8842. doi:10.1128/JVI.0075206

Drosten, C., Kummerer, B. M., Schmitz, H., \& Gunther, S. (2003). Molecular diagnostics of viral hemorrhagic fevers. Antiviral Res, 57 (1-2), 61-87. doi:10.1016/s0166-3542(02)00201-2

Dumitrescu, V. G., Vladimirescu, A. F., Moraru, A. F., Necsulescu, M., Ciulacu-Purcărea, V., Ionescu, L. E., . . . Nicolescu, G. (2014). The Hyaloma marginatum (potential vector of CCHFv) ectoparasite tick on Spur-Thighed tortoise (Testudo graeca iberica) in Dobrudja (Romania). Paper presented at the The 19th Conference E-SOVE, Greece.

Ergonul, O. (2006). Crimean-Congo haemorrhagic fever. Lancet Infect Dis, 6 (4), 203-214. doi:10.1016/S1473-3099(06)70435-2

Estrada-Pena, A., Zatansever, Z., Gargili, A., Aktas, M., Uzun, R., Ergonul, O., \& Jongejan, F. (2007). Modeling the spatial distribution of crimean-congo hemorrhagic fever outbreaks in Turkey. Vector Borne Zoonotic Dis, 7 (4), 667-678. doi:10.1089/vbz.2007.0134

Estrada, D. F., \& De Guzman, R. N. (2011). Structural characterization of the Crimean-Congo hemorrhagic fever virus Gn tail provides insight into virus assembly. J Biol Chem, 286 (24), 21678-21686. doi:10.1074/jbc.M110.216515

Gale, P., Estrada-Pena, A., Martinez, M., Ulrich, R. G., Wilson, A., Capelli, G., . . . Fooks, A. R. (2010). The feasibility of developing a risk assessment for the impact of climate change on the emergence of Crimean-Congo haemorrhagic fever in livestock in Europe: a review. J Appl Microbiol, 108 (6), 1859-1870. doi:10.1111/j.1365-2672.2009.04638.x

Gergova, I., \& Kamarinchev, B. (2013). Comparison of the prevalence of Crimean-Congo hemorrhagic fever virus in endemic and non-endemic Bulgarian locations. J Vector Borne Dis, 50 (4), 265-270.

Honig, J. E., Osborne, J. C., \& Nichol, S. T. (2004). Crimean-Congo hemorrhagic fever virus genome L RNA segment and encoded protein. Virology, 321 (1), 29-35. doi:10.1016/j.virol.2003.09.042

Hoogstraal, H. (1979). The epidemiology of tick-borne Crimean-Congo hemorrhagic fever in Asia, Europe, and Africa. J Med Entomol, 15 (4), 307-417. doi:10.1093/jmedent/15.4.307

Humolli, I., Dedushaj, I., Zupanac, T. A., \& Mucaj, S. (2010). Epidemiological, serological and herd immunity of Crimean-Congo haemorrhagic fever in Kosovo. Med Arh, 64 (2), 91-93.

Leblebicioglu, H., Eroglu, C., Erciyas-Yavuz, K., Hokelek, M., Acici, M., \& Yilmaz, H. (2014). Role of migratory birds in spreading Crimean-Congo hemorrhagic fever, Turkey.Emerg Infect Dis, 20 (8), 13311334. doi:10.3201/eid2008.131547

Mehravaran, A., Moradi, M., Telmadarraiy, Z., Mostafavi, E., Moradi, A. R., Khakifirouz, S., . . Chinikar, S. (2013). Molecular detection of Crimean-Congo haemorrhagic fever (CCHF) virus in ticks from southeastern Iran. Ticks Tick Borne Dis, 4 (1-2), 35-38. doi:10.1016/j.ttbdis.2012.06.006

Mostafavi, E., Haghdoost, A., Khakifirouz, S., \& Chinikar, S. (2013). Spatial analysis of Crimean Congo hemorrhagic fever in Iran. Am J Trop Med Hyg, 89 (6), 1135-1141. doi:10.4269/ajtmh.12-0509

Nasirian, H. (2020). New aspects about Crimean-Congo hemorrhagic fever (CCHF) cases and associated fatality trends: A global systematic review and meta-analysis.Comp Immunol Microbiol Infect Dis, 69 , 101429. doi:10.1016/j.cimid.2020.101429

Papa, A., Pappa, S., Panayotova, E., Papadopoulou, E., \& Christova, I. (2016). Molecular epidemiology of Crimean-Congo hemorrhagic fever in Bulgaria-An update. $J$ Med Virol, 88 (5), 769-773. doi: $10.1002 /$ jmv. 24400 
Papa, A., Sidira, P., Kallia, S., Ntouska, M., Zotos, N., Doumbali, E., . . . Tsatsaris, A. (2013). Factors associated with IgG positivity to Crimean-Congo hemorrhagic fever virus in the area with the highest seroprevalence in Greece. Ticks Tick Borne Dis, 4 (5), 417-420. doi:10.1016/j.ttbdis.2013.04.003

Răileanu, C., Anită, A., Porea, D., \& Savuta, G. (2015). Mise en evidence serologique de l'infection a virus de la fievre hemorragique Crimee-Congo chez les petits ruminants dans le sud-est de la Roumanie. Épidémiol. et santé anim.

Sas, M. A., Vina-Rodriguez, A., Mertens, M., Eiden, M., Emmerich, P., Chaintoutis, S. C., . . Groschup, M. H. (2018). A one-step multiplex real-time RT-PCR for the universal detection of all currently known CCHFV genotypes. J Virol Methods, 255 , 38-43. doi:10.1016/j.jviromet.2018.01.013

Shepherd, A. J., Swanepoel, R., Cornel, A. J., \& Mathee, O. (1989). Experimental studies on the replication and transmission of Crimean-Congo hemorrhagic fever virus in some African tick species. Am J Trop Med Hyg, 40 (3), 326-331. doi:10.4269/ajtmh.1989.40.326

Spengler, J. R., Bergeron, E., \& Rollin, P. E. (2016). Seroepidemiological Studies of Crimean-Congo Hemorrhagic Fever Virus in Domestic and Wild Animals. PLoS Negl Trop Dis, 10 (1), e0004210. doi:10.1371/journal.pntd.0004210

Weaver, S. C. (2006). Evolutionary influences in arboviral disease. Curr Top Microbiol Immunol, 299 , 285-314. doi:10.1007/3-540-26397-7_10

Wolfel, R., Paweska, J. T., Petersen, N., Grobbelaar, A. A., Leman, P. A., Hewson, R., . . Drosten, C. (2007). Virus detection and monitoring of viral load in Crimean-Congo hemorrhagic fever virus patients. Emerg Infect Dis, 13 (7), 1097-1100. doi:10.3201/eid1307.070068

Zeller, H. G., Cornet, J. P., Diop, A., \& Camicas, J. L. (1997). Crimean-Congo hemorrhagic fever in ticks (Acari: Ixodidae) and ruminants: field observations of an epizootic in Bandia, Senegal (1989-1992). J Med Entomol, 34 (5), 511-516. doi:10.1093/jmedent/34.5.511

Table 1. The distribution of tick collection sites in Tulcea county

\begin{tabular}{lll}
\hline Locality & Number of ticks & Tick species \\
\hline Cataloi & 18 & Rhipicephalus sp. \\
Slava Rusă & 27 & Rhipicephalus sp. \\
Slava Cercheză & 17 & Rhipicephalus sp. \\
Somova & 18 & Rhipicephalus sp. \\
Sat Pescăresc & 47 & Dermacentor sp. \\
TOTAL & $\mathbf{1 2 7}$ & \\
\hline
\end{tabular}

Table 2. Pooling protocol (grouping by sample place, species and site)

\begin{tabular}{lllll}
\hline Sample type & Site & Ticks number & Ticks genus & Sampling origin \\
\hline 1. Tick pool & Sat Pescăresc, Tulcea & 7 & Dermacentor sp. & Environment \\
2. Tick pool & Sat Pescăresc, Tulcea & 10 & Dermacentor sp. & Environment \\
3. Tick pool & Sat Pescăresc, Tulcea & 10 & Dermacentor sp. & Environment \\
4. Tick pool & Sat Pescăresc, Tulcea & 5 & Dermacentor sp. & Environment \\
5. Tick pool & Sat Pescăresc, Tulcea & 5 & Dermacentor sp. & Environment \\
6. Tick pool & Sat Pescăresc, Tulcea & 10 & Dermacentor sp. & Environment \\
7. Tick pool & Cataloi, Tulcea & 5 & Rhipicephalus sp. & Adult sheeps \\
8. Tick pool & Cataloi, Tulcea & 15 & Rhipicephalus sp. & Adult goats \\
9. Tick pool & Slava Rusă, Tulcea & 11 & Rhipicephalus sp. & Adult goats \\
10. Tick pool & Slava Rusă, Tulcea & 16 & Rhipicephalus sp. & Adult sheeps
\end{tabular}




\begin{tabular}{lllll}
\hline Sample type & Site & Ticks number & Ticks genus & Sampling origin \\
\hline 11. Tick pool & Slava Cercheză, Tulcea & 15 & Rhipicephalus sp. & Adult goats \\
12. Tick pool & Somova, Tulcea & 5 & Rhipicephalus sp. & Adult sheeps \\
13. Tick pool & Somova, Tulcea & 13 & Rhipicephalus sp. & Adult goats \\
\hline
\end{tabular}

Table 3. Results obtained using RT-qPCR for the presence of

CCHFV in ticks from Tulcea county

\begin{tabular}{lll}
\hline Locality & Tick genus & No. of CCHFV positive ticks \\
\hline Cataloi & Riphicephalus sp. & $0 / 18$ \\
Slava Rusă & Riphicephalus sp. & $0 / 27$ \\
Slava Cercheză & Riphicephalus sp. & $0 / 17$ \\
Somova & Riphicephalus sp. & $0 / 18$ \\
Sat Pescăresc & Dermacentor sp. & $0 / 47$ \\
\hline
\end{tabular}

